\title{
Risk Factors, Self-perceived Stress, and Clinical Training among Dentistry Students in Peru: A Cross-sectional Study
}

\author{
Edith Terán ${ }^{1}$, Frank Mayta-Tovalino²
}

\begin{abstract}
Introduction: This is a cross-sectional research on the impact of academic stress to which Peruvian students of dentistry are exposed and the various risk factors that affect academic performance and clinical and preclinical training.

Aim: The aim of this study is to determine the association of the perceptions of stress and the risk factors in students who take preclinical and clinical courses of a Peruvian private university.

Materials and methods: This cross-sectional study evaluated 222 students of the School of Dental Medicine at the Universidad Privada de Ciencias Aplicadas (UPC). To measure stress levels, we used the Dental Environment Stress (DES) questionnaire that was previously validated in Spanish. Data, such as age, sex, and year of study, were collected in a file made for this study. The students belonged to the 1 st and the 5 th year of study and authorized their participation through informed consent. In the data analysis, the odds ratio and the Chi-square test were used.

Results: We found that clinical students have 2.96 times higher risk of having stress than preclinical students. Within these categories, in the preclinical level, the first-year students show the higher stress levels (68.2\% in moderately stressful and very stressful $15.1 \%)$, while in the clinical level, the third-year students had a higher stress level ( $80.9 \%$ in moderately stressful and $19 \%$ in very stressful). Our data show no association between sex and stress levels of the students $(p=0.508)$.

Conclusion: Clinical students show more stress level with 2.96 times higher risk for stress compared to preclinical students. In the preclinical level, the first-year students showed a higher stress level, while in the clinical level, third-year students had a higher stress level. Our data show no association between sex and stress levels of students.

Clinical significance: The impact of stress on dentistry students significantly influences their performance at the time of performing dental treatment protocols. This research shows the direct relationship that exists between these variables.

Keywords: Clinical training, Dental student, Peruvian university, Self-perceived stress.

The Journal of Contemporary Dental Practice (2019): 10.5005/jp-journals-10024-2558
\end{abstract}

\section{INTRODUCTION}

For a long time, dentistry has been a demanding profession that generates much physical and mental strain on the professional. On many occasions, it has been observed that some students begin to experience stress when they begin the clinical practices of the Dental School, because at this time, they begin to perform their practices in real patients, in addition to receiving theoretical content, laboratory practices, and simulation dental. ${ }^{1,2}$

University teachers seek to train health professionals who are ethical and competent to practice general dentistry at a level commensurate with the expectations of the society and in the best possible way. Undergraduate dental education uses pedagogical procedures on specific competences, in such a way that it facilitates the student to obtain the necessary academic, clinical, and interpersonal skills within the curriculum of the professional career. ${ }^{1}$

Stress is described as a general mechanism of the body to adapt to all the influences, changes, demands, and tensions that could be exposed by the person, being common in all these processes the way the body tries to adapt, where sometimes the welfare of the person is endangered and can have a detrimental effect on academic performance. Teachers must monitor the level of stress that could be generated in students in relation to the academic subject, take measures to reduce the generating factors, and promote students to generate management tools to control stress situations that arise in their future profession. It has been shown in

\footnotetext{
${ }^{1,2}$ School of Dentistry, Universidad Peruana de Ciencias Aplicadas UPC, Lima, Peru
}

Corresponding Author: Frank Mayta-Tovalino, School of Dentistry, Universidad Peruana de Ciencias Aplicadas UPC, Lima, Peru, Phone: +51 16197000, e-mail: estadistico2.0@gmail.com

How to cite this article: Terán E, Mayta-Tovalino F. Risk Factors, Selfperceived Stress and Clinical Training among Dentistry Students in Peru: A Cross-sectional Study. J Contemp Dent Pract 2019;20(5):561-565.

Source of support: Nil

Conflict of interest: None

many studies that physical and mental illness, boredom at work, professional burnout, and a potential inhibitor in the performance of work are the most important causes of some diseases like stress. ${ }^{3,4}$

For this reason, dentistry schools should make every effort to balance the demands of academic and clinical training to obtain quality in the work of students. This challenge has led to considerable interest in identifying sources of stress for students in dental education programs. These signals are easily detectable in daily activities by a set of psychic or organic signs that produce alarm states that induce the individual to the so-called struggle or fleeing that end in adaptation or exhaustion that can contribute to general or specific stress disorders. ${ }^{5-11}$

Therefore, the objective of this study was to examine the prevalence of stress among dentistry students in Peru, to identify

() The Author(s).2019 Open Access This article is distributed under the terms of the Creative Commons Attribution 4.0 International License (https://creativecommons. org/licenses/by-nc/4.0/), which permits unrestricted use, distribution, and non-commercial reproduction in any medium, provided you give appropriate credit to the original author(s) and the source, provide a link to the Creative Commons license, and indicate if changes were made. The Creative Commons Public Domain Dedication waiver (http://creativecommons.org/publicdomain/zero/1.0/) applies to the data made available in this article, unless otherwise stated. 
the triggers that are risk factors, and to investigate the perceived impact of stress on their daily activities and mood during their training as future professionals.

\section{Materials and Methods}

This cross-sectional study included all the students enrolled, who attended classes in the School of Dentistry of the Peruvian University of Applied Sciences (UPC), in Peru. The dental school follows a 5-year curriculum. Therefore, this research evaluated 222 officially enrolled students. The Dental Environment Stress (DES) questionnaire was created by Garbee et al. ${ }^{9}$ and validated in Spanish by Fonseca et al. ${ }^{11}$ was used in this investigation. The sample was calculated using the proportions' comparison formula, establishing a significance level of 0.05 and a test power of 0.80 ; in addition, the subjects were evaluated by means of a simple random sampling. The study was approved by the Ethics and Research Committee of the Faculty of Health Sciences of the UPC with the approval code PI071-2013. Finally, it is worth mentioning that the elaboration and execution of this research followed the guidelines established by the Strengthening the Reporting of Observational Studies in Epidemiology (STROBE) (the reporting of observational studies in epidemiology) guidelines, thus guaranteeing the methodological and statistical rigor of the results obtained.

A letter of authorization was presented to the academic director of the professional career, to carry out the data collection of the students from the 1st to the 10th cycle. The students of the dental school from the 1st to 5th year of the UPC in their different venues were evaluated. Before the selection of the probabilistic sampling and after the call, the informed consent was voluntarily granted to each one of the participants. Underage students received an informed consent form before completing the questionnaire.

The dental clinic of the UPC was the main venue to collect the data and conduct the questionnaire to students from the 5 th to the 10th cycle who took clinical courses. Subsequently, the Campus Villa of the UPC was visited to evaluate the students from the 1st to the 4th cycle who had preclinical courses and who had the authorization of their parents.

The survey was evaluated according to the instrument called "DES" and some data were added, such as age, sex, workload, and year of study. The questionnaire had 30 questions to mark according to how they felt in various situations related to the academic life they have during their dental career. The categories to be chosen were "non-stressful," "slightly stressful," "moderately stressful," "very stressful," and "not relevant" in case the statement is not consistent with their life situation. The survey took a maximum of 10 minutes and was conducted during class hours to ensure that all students were present. Finally, the surveys were classified and transferred to a database created for the corresponding statistical analysis.

The analysis of the data was performed using Stata ${ }^{\circledR}$ statistical software 12.0. For the univariate analysis, we proceeded to obtain the descriptive statistics (frequency and prevalence) of the qualitative variables of the study, recorded in a frequency table. Normal distribution was determined by using the KolmogorovSmirnov test. For the bivariate analysis, the Chi-squared test, odds ratio, was used to determine the risk factors associated with the stress level, and the Mann-Whitney $U$ test to compare the variables.

\section{Results}

In the descriptive statistical analysis of the variables year and gender, it was found that the preclinical students were $52.7 \%$ and the clinical students were $47.3 \%$. It was also found that the percentage of the male gender was $33.3 \%$ and that of the female was $66.7 \%$ (Table 1).

Regarding gender, no difference was found statistically except in question 25 (work while studying), where it was observed that the female gender had a higher stress index with an average of $2.01 \pm$ 1.21 than the male gender with an average of $1.56 \pm 1.44$ (Table 2).

An analysis was made to associate the stress level of the students with the year of study, observing that the year with the highest level of stress was the fourth-year students with $27 \%$ of the total number of students that year, followed by the third-year students with a percentage of 19 of all students of that year. For the purposes of the study, the years of clinical and preclinical studies were categorized, observing that clinical students have a higher level of stress (18\%) than students who do not have clinical subjects (16.2\%). In addition, we can observe that there is a statistically significant association with stress and the year of study $(p=0.001)$ (Table 3).

In addition, a degree of association was established between the main stress variable and the year of study of the students of the School of Dentistry. It was found that the clinical students present 2.96 times higher risk than the preclinical students (Table 4).

\section{Discussion}

The present study used the questionnaire "DES", which was created by Garbee et al. ${ }^{9}$ and validated to Spanish by Fonseca et al. ${ }^{11}$ which determines the degree of stress of the students who follow the career of dentistry. This instrument was used in several investigations that evaluated the level of stress, ${ }^{11-19}$ which was the general objective of the present investigation.

Stress was defined as a situation or thought that makes one feel frustrated, angry, or anxious; it can be measured by several instruments. One of them, the one most used at the moment for research studies, is DES. This questionnaire has the advantages of presenting direct questions with direct answers (because the response scale has only five options), it takes only a few minutes to answer and has been used in many investigations. We evaluated $74(33 \%)$ students of the male gender and 148 (67\%) of the female gender of the School of Dentistry of the UPC. In several studies, it has been observed that the female gender prevailed in the dental population during the last years. Thus, in studies, such as those of Acharya, ${ }^{7}$ Polychronopoulou, ${ }^{8}$ Muirhead, ${ }^{15}$ Gorter, ${ }^{17}$ and Abu-Ghazale, ${ }^{19}$ the majority of students are female, showing a situation consistent with the present study. However, there are studies, such as that of Tangade, ${ }^{20}$ which presented a sample made up of 304 students, where $60 \%$ was represented by the male gender. From the present study, it was possible to determine the average age of the students of the School, finding a value of $21.10 \pm 4.30$ in the male gender and $19.61 \pm 2.26$ in the female gender. This was

Table 1: Distribution of the gender and year of study of the students of the School of Dentistry

\begin{tabular}{lllll}
\hline Variable & Group & Frequency & (\%) & Total (\%) \\
\hline Academic & Pre-clinic & 117 & 52.7 & 100 \\
Level & Clinic & 105 & 47.3 & \\
Gender & Male & 74 & 33.33 & 100 \\
& Female & 14 & 66.67 & \\
\hline
\end{tabular}


Table 2: Comparison of the degree of stress of dental students according to gender

\begin{tabular}{|c|c|c|c|}
\hline Questions & Female & Male & p value \\
\hline 1: Amount of work in class & $2.68 \pm 0.85$ & $2.5 \pm 0.93$ & 0.291 \\
\hline 2: Difficulty of working in class & $2.54 \pm 0.81$ & $2.24 \pm 0.90$ & 0.323 \\
\hline 3: Competition for the notes & $3 \pm 0.99$ & $2.95 \pm 1.01$ & 0.609 \\
\hline 4: Patients who arrive late or do not make their appointments & $0.75 \pm 1.51$ & $3.18 \pm 1.52$ & 0.145 \\
\hline 5: Exams or notes & $3.15 \pm 1.02$ & $3 \pm 0.92$ & 0.181 \\
\hline 6: Atmosphere created by the clinical teaching staff & $0.53 \pm 1.07$ & $2.52 \pm 1.03$ & 0.232 \\
\hline 7: Difficulty learning precision manual skills & $0.48 \pm 1.03$ & $2.08 \pm 0.97$ & 0.069 \\
\hline 8: Difficulty in learning clinical procedures & $0.56 \pm 1.18$ & $2.08 \pm 0.93$ & 0.110 \\
\hline 9: Lack of adequate clinical staff in the clinic & $0.23 \pm 0.48$ & $1.91 \pm 0.93$ & 0.166 \\
\hline 10: Lack of security to be a successful dentistry student & $2.14 \pm 1.07$ & $1.85 \pm 1$ & 0.128 \\
\hline 11: Lack of self-confidence to be a successful dentist & $2.06 \pm 1.03$ & $1.82 \pm 0.98$ & 0.106 \\
\hline 12: Lack of time between seminars, laboratories or clinic & $0.58 \pm 1.23$ & $3.02 \pm 1.15$ & 0.201 \\
\hline 13: Provisions of the faculty & $2.17 \pm 1.13$ & $3.04 \pm 0.99$ & 0.429 \\
\hline 14: Lack of home atmosphere in the accommodation area & 0 & 0 & - \\
\hline 15: Compliance with graduation requirements & $2.24 \pm 1.50$ & $3.37 \pm 0.94$ & 0.126 \\
\hline 16: Lack of input in the decision-making process of the faculty & $2.23 \pm 1.16$ & $2.83 \pm 1$ & 0.276 \\
\hline 17: Insecurity relative to the professional future & $2.36 \pm 1.12$ & $2.58 \pm 0.95$ & 0.310 \\
\hline 18: Financial responsibilities & $2.27 \pm 1.32$ & $2.5 \pm 1.30$ & 0.091 \\
\hline 19: Lack of time to perform the assigned tasks of the faculty & $2.85 \pm 1.01$ & $2.97 \pm 1.04$ & 0.981 \\
\hline 20: Inconsistency of feedback about their work among different instructors & $2.07 \pm 1.12$ & $1.98 \pm 1.19$ & 0.320 \\
\hline 21: Assistance and success in dental issues & $1.91 \pm 1.06$ & $2.91 \pm 1.01$ & 0.893 \\
\hline 22: Lack of communication or cooperation of patients & $0.64 \pm 1.32$ & $2.41 \pm 1.36$ & 0.265 \\
\hline 23: Lack of time to relax & $2.57 \pm 1.13$ & $3.13 \pm 1.01$ & 0.780 \\
\hline 24: Fear of not passing the course or year & $2.97 \pm 1.16$ & $3.43 \pm 0.90$ & 0.363 \\
\hline 25: Work while studying & $2.01 \pm 1.21$ & $1.56 \pm 1.44$ & 0.007 \\
\hline 26: Neglecting personal life & $2.34 \pm 1.19$ & $2.16 \pm 1.14$ & 0.323 \\
\hline 27: Fear of dealing with patients with contagious diseases & $0.62 \pm 1.24$ & $2.94 \pm 0.88$ & 0.165 \\
\hline 28: Delay in receiving notes & $2.51 \pm 1.09$ & $1.75 \pm 0.82$ & 0.750 \\
\hline 29: Lack of self-evaluation and awareness of one's competencies & $2.18 \pm 1.03$ & $2.24 \pm 0.85$ & 0.178 \\
\hline 30: Cooperation of the dental laboratory & $0.37 \pm 0.78$ & $2.95 \pm 1.43$ & 0.141 \\
\hline
\end{tabular}

Mann-Whitney $U$ test

Level of statistical significance $(p<0.05)$

Table 3: Association of stress level with the year of study and academic level of the students of the School of Dentistry

\begin{tabular}{|c|c|c|c|c|c|c|}
\hline \multirow[b]{2}{*}{ Variables } & \multicolumn{6}{|l|}{ Stress level } \\
\hline & Not stressful & Slightly stressful & Moderately stressful & Very stressful & Total & $p$ value* \\
\hline First year & $0(0 \%)$ & $11(16.6 \%)$ & $45(68.2 \%)$ & $10(15.1 \%)$ & $66(100 \%)$ & 0.001 \\
\hline Second year & $0(0 \%)$ & $12(23.5 \%)$ & $30(58.8 \%)$ & $9(17.6 \%)$ & $51(100 \%)$ & \\
\hline Third year & $0(0 \%)$ & $0(0 \%)$ & 34 (80.9\%) & $8(19 \%)$ & $42(100 \%)$ & \\
\hline Fourth year & $0(0 \%)$ & $0(0 \%)$ & 27 (72.9\%) & $10(27 \%)$ & 27 (100\%) & \\
\hline Fifth year & $1(3.84 \%)$ & 7 (26.9\%) & $17(65.3 \%)$ & $1(3.84 \%)$ & $26(100 \%)$ & \\
\hline Total & 1 & 30 & 153 & 38 & 222 & \\
\hline Preclinic & $0(0 \%)$ & $23(19.6 \%)$ & 75 (64.1\%) & $19(16.2 \%)$ & $117(100 \%)$ & 0.001 \\
\hline Clinic & $1(0.95 \%)$ & $7(6.6 \%)$ & 78 (74.2\%) & $19(18.0 \%)$ & 105 (100\%) & \\
\hline Total & 1 & 30 & 153 & 38 & 222 & \\
\hline
\end{tabular}

*Chi-square test

Level of statistical significance $(p<0.05)$

similar to other studies, such as Harikiran, ${ }^{1}$ where it was observed that the mean age was $21.2 \pm 0.7$, and in the Tangade study, ${ }^{20}$ where the average age was $20.65 \pm 2.07$.

The perception of stress was determined through DES in 222 students of the career. According to the average scores of the questions in the questionnaire, it was observed that the highest average was obtained in question 24 (fear of not passing the course or the year), followed by question 5 (exams or notes), question 3 (competition for grades), question 19 (lack of time to complete the tasks assigned by the faculty), and question 23 (lack of time to 
Table 4: Magnitude of association (OR) of the level of stress with the year of study of the students of the School of Dentistry

\begin{tabular}{|c|c|c|c|c|}
\hline & & \multicolumn{3}{|c|}{ Degree of stress } \\
\hline & & \multirow{2}{*}{$\begin{array}{l}\text { Not stressed } \\
\text { OR }\end{array}$} & \multicolumn{2}{|l|}{ Stressed } \\
\hline & & & $95 \% \mathrm{Cl}$ & $p$ value \\
\hline \multirow[t]{2}{*}{$\begin{array}{l}\text { Year of } \\
\text { study }\end{array}$} & $\begin{array}{l}\text { Preclinic (1st and } \\
2 \text { nd year) }\end{array}$ & 2.966 & $1.264-6.962$ & 0.012 \\
\hline & $\begin{array}{l}\text { Clinic ( } 3 \text { rd, } 4 \text { th, } \\
\text { and } 5 \text { th year }\end{array}$ & & & \\
\hline
\end{tabular}

Level of statistical significance $(p<0.05)$

relax) successively. These results were similar to the Fonseca study, ${ }^{11}$ where question 24 generated greater stress followed by questions 5 , 23,19 , and 4 . The research carried out by Muirhead ${ }^{15}$ found that the items that generate a higher stress index were question 5 followed by questions 23 and 3 . In Saxena's study, ${ }^{18}$ a similar situation was found, where question 27 presented a higher stress load followed by questions 5 and 24 in dentistry students in the city of Bhopal, India. Also, it could be observed in Sedky's study ${ }^{2}$ that the items that generated the highest stress index were questions 19, 12, 1, and 5 successively.

These results may be due to the fact that the level of academic demand is quite high in the school, where the number of requirements to pass the clinical course is extensive, generating a lack of time to perform the assigned tasks (despite the students' ample hours), and lack of time to relax. Another possible cause may be due to the students' interest in reaching the maximum grade, in such a way that they compete among themselves to stand out in the group, which generates some stress because they fear not achieving this purpose. On the contrary, the students of the School of Dentistry of the UPC obtained the lowest average in questions 9 (lack of adequate clinical staff in the clinic) and questions 7 (difficulty to learn precision manual skills). This may be due to the close relationship between students and teachers and the small number of students per year of study, allowing the teaching to be more personalized. These results were discordant to the Muirhead study. ${ }^{15}$ This author presented that question 14 (lack of home atmosphere in the accommodation area) was the one with the lowest stress index, which cannot be compared with our study because our school does not have accommodation services. On the contrary, this author presented that questions 9 and 7 presented light or moderate stress in the students. There are numerous research studies that have evaluated these variables that mention the direct relationship that exists between them, directly affecting the capacity of the subjects evaluated. ${ }^{21-27}$

Another important variable in the investigation was the year of study. For the purposes of the study, it was categorized into clinical (3rd, 4th, and 5th year) and preclinical (1st and 2nd year). This characteristic was also taken by other authors, such as Suha Abu-Ghazaleh, ${ }^{19}$ where he also categorized the $1 \mathrm{st}, 2 \mathrm{nd}$, and 3rd year students as preclinical students and 4th and 5th year as clinical students. Also, Muirhead ${ }^{15}$ categorized the 1 st and 2 nd year students as preclinical and the $3 \mathrm{rd}$ and 4 th year students as clinical, so it was convenient to use this variable as a general objective. This is discordant to other authors, such as Bedoya ${ }^{4}$ and Acharya, ${ }^{7}$ who take the categorization only for years of study.

In Peru, training in the professional career of dentistry lasts 10 academic years (5 years). The curriculum includes subjects of general culture, basic sciences, preclinical training, and clinical training. This situation is quite similar in countries like Brazil and Colombia. On the contrary, in the United States, universities do not teach undergraduate programs in dentistry, people who plan to choose that career must meet certain prerequisites, among which some are taught by the American Dental Association (ADA), which include 8-hour courses in Biology, Physics, English, General Chemistry, and Organic Chemistry; and requirements by the Schools of Dentistry. It is not necessary to graduate in any of the sciences mentioned, but it is a prerequisite to have taken those courses and then apply for the Dentistry Admission Examination (DAE). Finally, they must complete 4 more years to achieve the professional degree, of which 2 years are devoted to the basic medical sciences and 2 years to acquire a clinical orientation. ${ }^{28}$

In this study, it was found that the stress level of preclinical students (16.2\% very stressful) was lower than that of the students who study clinical subjects ( $18 \%$ very stressful). The students with the highest level of stress were the fourth-year students with $27 \%$ of all students of that year, followed by the third-year students with a percentage of 19 of all students of that year. This may be due to the fact that the students begins to perform their clinical practices in real patients after the 3rd year, in addition to the number of hours per week increasing with the years of study. In the case of the fourth-year students, they have a higher workload compared to the rest of the students. These results were similar to the study of Suha Abu-Ghazaleh, ${ }^{19}$ where he showed that the level of stress increases over the years, determining that the 1st year had a lower level of stress and the 5th year he had higher levels of stress.

The gender variable was also used, in which it was categorized into feminine and masculine. This variable was also taken by various authors such as Harikiran, ${ }^{1}$ Sedky, ${ }^{2}$ Madhan, ${ }^{3}$ among others. In the present study, it was observed that female students $(74.77 \%)$ have higher levels of stress than male students (25.22\%). This may be because women are three times as vulnerable as men to low moods. There are studies that show that the rate of production of serotonin in the brain of men is $52 \%$ higher than in women. These results are similar to the studies conducted by Sedky ${ }^{2}$ and Acharya, ${ }^{7}$ but it is discordant to the Polychronopoulou study, ${ }^{12}$ where it shows statistically significant difference between the female and the male gender.

Finally, the most important limitation in this study was to survey the entire population of students of the School of Dentistry, because not all students carry all the courses they have to take in their academic cycle or were absent on the day of the survey. On the contrary, another limitation is the fact that the sample was mostly female students. Previous studies have found that female students of dental schools show higher levels of stress than male students.

\section{Conclusion}

A greater degree of stress was found in the students of the clinic than in the preclinical students. Among the preclinical students, the students who presented the highest degree of stress were the 1st year students, while within the group of the students of the clinic, the students who presented the highest degree of stress were the 3rd year students. In addition, it was observed that the students belonging to the clinical group have $\mathrm{OR}=2.96, \mathrm{Cl} 95 \%=1.264-6.962$ in comparison to the preclinical students. The Spanish version of the DES-30 questionnaire did well, but we need future studies. Dental school-wide strategies to prevent high levels of stress, as well as provision of counseling and interventions to students who need it, are necessary to maintain a positive academic environment. 


\section{ACKNOWLedgments}

The authors wish to thank the Director of the School of Dentistry of Universidad Peruana de Ciencias Aplicadas (UPC) for his invaluable support for the execution and development of this research work.

\section{References}

1. Harikiran AG, Srinagesh J, et al. Perceived sources of stress amongst final year dental under graduate students in a dental teaching institution at Bangalore, India: a cross sectional study. Indian J Dent Res 2012;23(3):331-336. DOI: 10.4103/0970-9290.102218.

2. Sedky NA. Perceived Sources of Stress among Junior \& Mid-Senior Egyptian Dental Students. Int J Health Sci 2012;6(2):141-157.

3. Silva O, Palomino S, et al. J Environ Public Health 2018;2018:1-7.

4. Bedoya SA, Perea M, et al. Evaluación de niveles, situaciones generadoras y manifestaciones de estrés académico en alumnos de tercer y cuarto año de una Facultad de Estomatología. Rev Estomatol Herediana 2006;16(1):15-20.

5. Jaramillo G, Caro H, et al. Dispositivos desencadenantes de estrés y ansiedad en estudiantes de Odontología de la Universidad de Antioquia. Rev Fac Odont Antioq 2008;20(1):49-57.

6. Preciado-Serrano M, Vasuezz-Goñi JM. Stress profile and burnout syndrome in mexican dental students of a public university. Rev Chil Neuro-Psiuiat 2010;48(1):11-19.

7. Acharya S. Factors affecting stress among Indian dental students. J Dent Educ 2003;67(10):1140-1148.

8. Polychronopoulou A, Divaris K. Dental students' perceived sources of stress: a multi-country study. J Dent Educ 2009;73(5):631-639.

9. Garbee WH Jr, Zucker SB, et al. Perceived sources of stress among dental students. J Am Dent Assoc 1980;100(6):853-857.

10. Kumar S, Dagli RJ, et al. Perceived sources of stress amongst Indian dental students. Eur J Dent Educ 2009;13(1):39-45. DOI: 10.1111/j.16000579.2008.00535.x.

11. Fonseca J, Divaris K, et al. Perceived sources of stress amongst Chilean and Argentinean dental students. Eur J Dent Educ 2013;17(1):30-38. DOI: 10.1111/eje.12004.

12. Polychronopoulou A, Divaris K. Perceived sources of stress among Greek dental students. J Dent Educ 2005;69(6):687-692.

13. Sugiura G, Shinada K, et al. Psychological well-being and perceptions of stress amongst Japanese dental students. Eur J Dent Educ 2005;9(1):17-25. DOI: 10.1111/j.1600-0579.2004.00352.x.

14. Sofola OO, Jeboda SO. Perceived sources of stress in Nigerian dental students. Eur J Dent Educ 2006;10(1):20-23. DOI: 10.1111/j.16000579.2006.00391.x
15. Muirhead V, Locker D. Canadian dental students' perceptions of stress and social support. Eur J Dent Educ 2008;12(3):144-148. DOI: 10.1111/j.1600-0579.2008.00512.x.

16. Morse Z, Dravo U. Stress levels of dental students at the Fiji School of Medicine. Eur J Dent Educ 2007;11(2):99-103. DOI: 10.1111/j.16000579.2007.00435.x

17. Gorter R, Freeman R, et al. Psychological stress and health in undergraduate dental students: fifth year outcomes compared with first year baseline results from five European dental schools. Eur J Dent Educ 2008;12(2):61-68. DOI: 10.1111/j.16000579.2008.00468.x.

18. Saeed A, Bahnassy A, et al. Perceived stress and associated factors among medical students. J Family Community Med 2016;23(3): 166-171. DOI: 10.4103/2230-8229.189132.

19. Abu-Ghazaleh SB, Rajab LD, et al. Psychological stress among dental students at the University of Jordan. J Dent Educ 2011;75(8): 1107-1114.

20. Tangade PS, Mathur A, et al. Assessment of Stress Level among Dental School Students: An Indian Outlook. Dent Res J 2011;8(2): 95-101.

21. Alzahem AM, van der Molen HT, et al. Stress amongst dental students: a systematic review. Eur J Dent Educ 2011;15(1):8-18. DOI: 10.1111/j.1600-0579.2010.00640.x.

22. Divaris K, Polychronopoulou A, et al. Stress and burnout in postgraduate dental education. Eur J Dent Educ 2012;16(1):35-42. DOI: 10.1111/j.1600-0579.2011.00715.x.

23. Halboub E, Alhajj MN, et al. Perceived Stress among Undergraduate Dental Students in Relation to Gender, Clinical Training and Academic Performance. Acta Stomatol Croat 2018;52(1):37-45. DOI: 10.15644/ asc52/1/6.

24. Al-Samadani KH, Al-Dharrab A. The Perception of Stress among Clinical Dental Students. World J Dent 2013;4(1):24-28.

25. Cardoso C, Loureiro L, et al. Pediatric dental treatment: Manifestations of stress in patients, mothers and dental school students. Braz Oral Res 2004;18(2):150-155.

26. Sanders $A E$, Lushington $K$. Effect of perceived stress on student performance in dental school. J Dent Educ 2002 Jan;66(1):75-81.

27. Newbury $D$, Lowry $R$, et al. The changing patterns of drinking illicit drug use, stress, anxiety and depression in dental students in a UK dental school: a longitudinal study. Br Dent J 2002;192(11): 646-649.

28. Terán E. Asociación de la percepción de estrés de los estudiantes que cursan asignaturas preclinicas con los que cursan asignaturas clínicas en la Escuela de Odontología de la UPC durante el 2013. Thesis Lima, Peru: Universidad Peruana de Ciencias Aplicadas, 2014. 